\title{
ADVERTISING LANGUAGE: A PRAGMATIC APPROACH TO CIGARETTE ADVERTISEMENTS IN INDONESIA
}

\author{
Ahmad Muammar Qadafi ${ }^{1}$ \\ Ribut Wahyudi² \\ Faculty of Humanities, Maulana Malik Ibrahim State Islamic University, \\ Malang, Indonesia \\ daf_fi@yahoo.com ${ }^{1}$ \\ r.wahyudi.vuw.nz@gmail.com²
}

\begin{abstract}
In Indonesia, it has been a public knowledge that cigarette is dangerous to consume. However, the involvement of advertisement and its huge economic benefit has driven the government to freely let cigarette be widely promoted; nevertheless the image of the cigarette would not be shown on the screen as per agreement with advertisers. These series of complexities in the cigarette advertisements have attracted the authors to investigate the way cigarettes are promoted without explicitly exposing them. Using inferential pragmatic approach (Sperber \& Wilson, 2002), this research reveals that the language of advertisements operate subtly at the level of cognition and comprehension to persuade smokers.
\end{abstract}

Keywords: Cigarette, advertising language, pragmatics, Indonesia advertisement, Indonesia

\section{Introduction}

In Indonesia, advertisements have become a major agent to influence society recently. As a major controller in the society, they can softly command and shape the society as they want (Tanaka, 1994). The recent advertisements have shown how effective they are to influence society through the many ways of advertising their product (Chang, 2013), which in this case is cigarette.

The government has legalised the cigarette advertisements with restrictions. Some words such as Slim, Premium, Special, Full Flavour, Light, Ultra-Light, Mild, Extra Mild, or other words that indicate the image or feeling of safety, quality, superiority, personality, and many other similar meanings are prohibited (Indonesian Republic Government Rule, 2003). This rule also includes the prohibition to display and illustrate children, teenagers, or pregnant women in the form of 
picture and wording and not to mention the squirrelling sentences (Indonesian Republic Government Rule, 2012). Despite these restrictions and controls, the cigarette advertisements are still blooming.

This research discusses how the advertisements have a high possibility to persuade society indirectly, since they are not actually "selling" the cigarette to people, due to the reasons mentioned previously. As advertisements vary according to media (e.g., television commercials, newspaper advertisements) and devices (smart phones, televisions, e-Readers, laptops) which carry along the makings of the advertisements (Rodgers and Thorson, 2012), the researchers had decided to limit this research to television based cigarette advertisements only (Brierley, 1995), and investigate the visual media displayed on news and television, in which the society in general can easily understand (Forceville, 1996).

Greece and Roman Empire were the first to come out with some kind of announcements (Dyer, 1982), and was regarded as the first ever recorded advertisement ever known in this modern world's history. Years after, it came during the time of newspapers, before the upcoming era of television as the first main media of moving pictures, before advertisements finally became an effective way to persuade and convince people to buy products offered. Up to now, there are major interests from numerous experts on how advertisements can bring a new world or way of lifestyle to every person in this world. Advertising has become a popular subject of study, approached from a wide range of disciplines, such as anthropology, sociology, linguistics, literary criticism, and media studies (Tanaka, 1994).

Advertisement comes from the Latin verb advertere, meaning "to turn towards" (Berger, 2011; Goddard, 1998), and it is undoubtedly true that adverts are texts that do their best to get our attention, to make us turn towards the product being sold. In its simplest sense the word "advertising" means "drawing attention to something", or in other words it may be interpreted as "notifying or informing somebody of something" (Berger, 2011; Dyer, 1982). In relation to this study, the Indonesian Government Law (Article 19, 2003) states that cigarette advertisement is an activity to introduce, publish and or promote the cigarette with or without the return of money to the society with the purpose to influence consumers to use the cigarette advertised; and in this case is in the Indonesian society. Advertisements are pervasive in the Indonesian television's daily program because it shows up almost every time we turn the television on (Goddard, 1998). They can actually persuade, convince, or even manipulate society about almost every single thing in this world (Tanaka, 1994).

Advertising is acknowledged as the engine that drives consumer purchase and, therefore, advertising "keeps the wheels of the economy turning" (Rodgers \& Thorson, 2012). The primary function of advertising is to introduce a wide range of consumer goods to the public and thus to support the free market economy (Dyer, 1982). On a global scale, the conduct of and relations between nations, organisations and individuals have been revised according to market models of promotion and competition (Crichton, 2010), in which on further implication will likely lead into the modern society inside the world of advertisements.

This argument came up due to the fact that the privatisation of diverse public services in areas such as energy, water, transport, prisons, social services, 
education, health and child care has been widespread, and commercial models of management have become the norm in such organisations (Crichton, 2010). In short, we can see clearly how this matter is highly supported by the development of advertisement under the background of particular country discussed in this paper.

\section{Previous Studies on Cigarette Advertising}

Research on cigarette advertising in culture and society studies (MacRury, 2009) and social discourse (Crichton, 2010; Cook, 1992) have shown how cigarette advertisements affect or impact the society. Studies indicate that a majority of the society tends to choose advertisements which are more likely to be in line with their own heritage and local culture, because heritage and local culture are inherited, and become the identity of almost everyone in this country. This is where the advertisements play a very crucial part to persuade the people.

Bruthiaux (2000) investigates the communicative mechanism brought by advertisements. This research is an exemplary result of how the advertisement can actually manipulate the audience through their wonderful display of image. The aspect of identity is also expounded deeply on this extent, based on the classification of both advertisement and type of audience.

There is a similar outcome when it involves communication of its intention to influence the audience (Crook, 2003). The language may be hidden, but the message can still be caught by the audience, depending on how the advertisements are displayed, regardless of the complicated word-play inside it. Belch and Belch (2003) reported an interesting study conducted to present how far a cigarette advertisement tries to commercialise the product in any way possible to attract consumers. It was found that when consumers start liking one product, they are unlikely to change to other cigarette brands.

Furthermore, another study about cigarette advertisements focussed on cultural economy and semiotics aspects (McFall, 2004). This study reveals that the habitual actions of how people do their daily economical-life can actually be influenced by advertisements. However, the authors were unable to draw conclusions about how advertisement directly causes people to adapt to what the advertisers want generally.

Velasco-Sacristan and Fuertes -Olivera (2005) initiated an interesting research on rhetorical language used in advertisements. The research resulted in a unique outcome where they could unmask the advertiser's rhetorical intentions to manifest certain non-neutral assumptions without making public its intentions to the target audience. In other words, advertisements can even drive the society to either choose or behave as what the advertisers would like them to, as long as the impact brought by the advertisements are strong enough to persuade them.

DiRocco and Shadell (2007) examined whether gender has any relation to the level of relaxation caused by cigarette advertisements and if it has any relationship with the intentions of non-smoking adolescents wanting to smoke. The result indicates that high relaxations increased intentions to smoke among female adults only. Further investigation is needed to identify the features of cigarette 
advertisements which have the most influential role among different groups of adolescents.

In the following year, Devra (2008) discusses the dilemma that government and industry face with regard to the fact that cigarette is toxic but indeed lucrative. He mentions that UK and US governments have helped industries with millions of dollars to produce safer cigarettes. This according to him is something called as, "modern hazard" that have social and economic realities with the society.

Viewing from different aspects, Freeman, Brucks, Wallendorf and Boland (2009) studied the youths' understanding about cigarette advertisements. Results show that youths are aware of the type of product an advertisement is promoting but they have low levels of awareness on brand understanding. It also shows that understanding cigarette advertisements is positively related to "susceptibility to smoking". These findings suggest a sort of psychological mechanism that permeates the link between cigarette advertising exposure and youth smoking.

The metaphor aspects of advertisements have indeed been found (Crichton, 2010). However, it is a mere explanation about the metaphor inside the mere pictures, but not inside the language as this research does (Forceville, 1996). Both of the writers can finally give sufficient information about metaphorical language, that both forms of language and picture can attract the audience to watch and or read the advertisements. It was also found that people tend to be attracted by how the advertisements display the play and they even liked it when advertisers used wordplay and so on.

Pelsmacker and Faseur (2010) examined the play of emotion in television advertisements to persuade people to purchase the products. This research also specifies the product classifications in which each of them had its own advertising style to persuade the audience, and cause them to engage with their emotions before buying the product; which is also quite effective based on the outcome. The study concluded that the consumers think that the products possess attitudes and their own nature, or in other words they see the product as something alive.

Additionally, Vizcaino (2011) while investigating how the advertising language can drive home its message even more and not directly sticking to the product, has found that this kind of language is used in the context for their symbolic and visual value rather than their content or informational components. The foreign language is used for symbolism rather than content. It is not conveyed at the referential level, but rather at the visual level of language (Forceville, 1996).

Pragmatics theory of advertisement on television has been written on how advertisements depict various meanings (Martinez-Camino \& Perez-Saiz, 2011). It contains the classification of advertisement, and also the main strategy of how the advertisers should commercialise something; an outcome drawn when one of the strategies is basically more effective than the others, and about how the consumers can actually choose the product based on the language used only. However, the absence of product classification for cigarette is missing from the research. Considering the important sequence of how the advertisement world is working, this classification is badly needed in research on advertising. This point of missing product was also researched to prove the referential and textual imagination produced by the audience (Gardner \& Luchtenberg, 1999). On this point, the 
research focuses on the mechanism of how people refer to and react toward the advertisements, including the relation between the advertisements and the product. They also described the how those waypoints (image, wordings and reference) are influenced by the culture in the society.

Paek, Reid, Jeong, Hoojon and Krugman (2012) examined frequencies and types of promotion techniques featured in five decades of cigarette advertising relative to five different major smoking eras. In general, the proportion of promotion in the advertisements rose constantly. This, they argue, require more attention from the experts of tobacco control and government regulators. In the subsequent year, Kostova and Blecher (2013) researched the cigarette advertisements and its estimated impacts. They found a positive correlation between smoking and advertising exposure as a result of the disproportionately higher tendency of smokers to observe advertising more properly than a direct causal effect of advertising on smoking. The complexity of language found in cigarette advertisements in Indonesia has been unexplored.

\section{Research Questions}

1. How can the language of cigarette advertisements be exploited to unconsciously attract smokers?

2. Are there any similar messages from language used in cigarette advertisement?

\section{Methodology}

The corpus will be taken from advertisements precluding the main show inside the television, in which the duration varies on every single advertisement. However, we have taken range of the time randomly with the variations of them as the same way. Since this research takes on pragmatic approach, the data are only in the form of phrase or sentence in the advertisements (Conrad, 2002). We take the exact methodology as Tanaka (1994) did in his book. Data were collected from the internet. We took exactly four examples of cigarette advertisements, and considered them as purposive sampling (Tashakkori and Cresswell, 2007 as cited in Litosseliti, 2010). Since the language analysed is from an electronic source, then they will be called as a corpus (Conrad, 2002).

In analysing the data, we employ Sperber and Wilson's (1996; 2002) inferential theory of pragmatics to make sense of the advertising language (Tanaka, 1994). Inferential theory of pragmatics originates from the theory of Gricean cooperative principle and maxims of (quality, quantity, relevance and manner) (Grice, 1975) which focuses only on relevance aspect (Sperber \& Wilson, 2002, p. 250). This theory comprises "two principles of relevance: cognitive principle and communicative principle" (p. 249). The first principle of relevance is "geared to the maximisation relevance" and the latter principle states that "utterances create expectation of optimal relevance". These cognitive and communicative principles are then narrowed down into sub-aspects. With regard to the analysis, we used only (1) relevance and cognition, (2) relevance and comprehension, (3) relevant and communications, and (4) relevant and mental architecture apply to two interactions 
in daily life communication where two or more speakers are engaged in conversation (see Sperber \& Wilson, 2002, pp. 249-290 for details).

Relevant and cognition is broken down into the following rules:

(1) Relevance of an input to an individual: (a) other things being equal, the greater the positive effects achieved by processing an input, the greater the relevance of the input to the individual at that time; and (b) Other things being equal, the greater the processing effort expended, the lower the relevance of the individual at the time; and

(2) Cognitive principle of relevance: human cognition tends to be geared to the maximisation of relevance. (Sperber \& Wilson, 2002, pp. 252-255)

Relevance and comprehension is subdivided into the following rules:

(a) Constructing an appropriate hypothesis about explicit content (explicatures) via decoding, disambiguation, reference resolution, and other pragmatic enrichment process;

(b) Constructing an appropriate hypothesis about the intended contextual assumptions (implicated premises); and

(c) Constructing an appropriate hypothesis about the intended contextual implications (implicated conclusions). (Sperber \& Wilson, 2002, p. 262)

Only certain words, which become the keywords or the key point of the sentence, were translated by using Cambridge (Digital) Learner's Dictionary $3^{\text {rd }}$ Edition (2008). There are four types of data collected from different cigarette companies to find how Indonesian audiences process an advertisement in general and cigarette advertisements in particular. These data act essentially as observational data (Silverman, 1994).

The analysis of the cigarette advertisements produced patterns on the effectiveness of the advertisement to promote the cigarette and the relation between the language of advertising and the nature of cigarette smoking. Needless to say, the utterances from the original advertisements are typed in bold and indicated with double quotation marks ("...") to emphasise that it is the actual sentence taken from the advertisements (Miles \& Huberman, 1994). The brand of the product is typed both in bold and capitalised. As the data are in Indonesian language, a translation is provided underneath the actual data in bold.

\section{Results and Discussion}

In this discussion, the researchers intentionally chose certain advertisements as evidences of complexities in the pragmatic approach itself. 


\section{Advertisement 1}

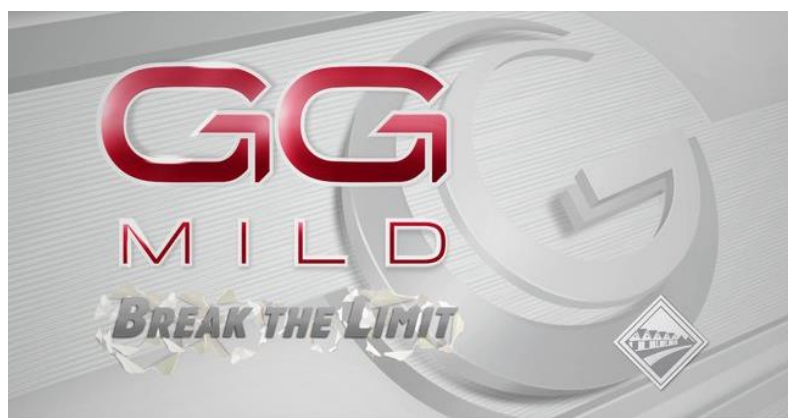

Source: "GG MILD, Break the Limit" http://vimeo.com/64474299

Table 1

Analysis of Advertisement 1

\begin{tabular}{|l|l|}
\hline Term & Possible Meaning \\
\hline Break & $\begin{array}{l}\text { 1. To (cause something to) separate suddenly or violently into } \\
\text { two or more pieces, or to (cause something to) stop working } \\
\text { by being damaged. }\end{array}$ \\
& $\begin{array}{l}\text { 2. To destroy or end something, or to come to an end. } \\
\text { 3. Fail to keep a law, rule or promise. } \\
\text { 4. To (cause something to) divide into two or more parts or } \\
\text { groups. }\end{array}$ \\
$\begin{array}{ll}\text { 5. To interrupt or to stop something for a short period. } \\
\text { 6. To go somewhere or do something by force. }\end{array}$ \\
$\begin{array}{l}\text { 7. To lose your self-control, confidence, determination, etc., or } \\
\text { to make someone do this. }\end{array}$ \\
$\begin{array}{l}\text { 8. To come or bring to notice; to (cause to) be known. } \\
\text { 9. To reach and move over the beach, hit a cliff or wall, etc. } \\
\text { 10. When dawn or day breaks, the sun starts to appear in the sky } \\
\text { early in the morning. } \\
\text { 11. If someone's voice breaks, it changes from one state to } \\
\text { another. } \\
\text { 12. In tennis to win a game in which another player is serving (= } \\
\text { hitting the ball first). }\end{array}$ \\
\hline $\begin{array}{l}\text { 1. The greatest amount, number or level of something that is } \\
\text { either possible or allowed. }\end{array}$ \\
2. INFORMAL the amount of something that is enough and not \\
too much.
\end{tabular}

Source: Cambridge (Digital) Learner's Dictionary $3^{\text {rd }}$ Edition (2008) 
There are many meaning inputs as shown in Table 1 . In relevance theory, we should "'pick out' an input that is of more relevance than any alternative input available to us" (Sperber \& Wilson, 2002, p. 252), then consequently we need an input which has "greater positive effect ... and greater relevance" (p. 252). From this first evidence, it can be seen that when the term "break" is combined with limit, the most suitable meaning which has greater positive effect and greater relevant is the intention to show and provoke people to go over the top of their maximal efforts, or break their own limit. This may lead to the message on how the work ethics of every individual should always be upheld on every way of condition, including about how the term closely relate with the power of men inside the boundary of identity and language (Abe, 2010).

Moreover, we can see that this also depicts an impression as a maximum effort of something, and also a power of men. This expression can also mean breaking the satisfaction limit, since one of the reasons why people smoke is to find satisfaction. On another guess, it can also mean that smokers can maximise their skill so that they can have enough power to achieve what they dreamed of. The above interpretations for us are more relevant compared to other potential meaning input as a cigarette product wants to align its image with smoker's maximum efforts in daily life.

In terms of relevance and comprehension, the company through its cigarette product explicates that breaking the limits means doing the maximum for one's effort. The implicated premise that the company projects draw is breaking the limit for human being can be inspired by consuming a cigarette product and the implicated conclusion is GG MILD is the right choice for people who want to break the limit, doing the maximum effort in their life.

\section{Advertisement 2}

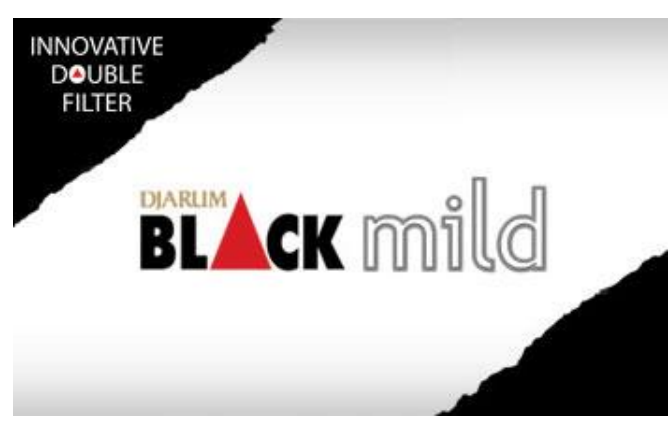

Source: DJARUM BLACK MILD, Innovative Double Filter http://www.blackxperience.com/index.php?page=events-detail\&aeid=2414)

Table 2

Analysis of Advertisement 2

\begin{tabular}{|l|l|}
\hline Term & Possible Meaning \\
\hline Innovative & 1. Using new methods or ideas. \\
\hline Filter & $\begin{array}{l}\text { 1. Any of several types of equipment or devices for removing solids } \\
\text { from liquids or gases, or for removing particular types of light. }\end{array}$ \\
\hline
\end{tabular}




\begin{tabular}{|l|l|}
\hline $\begin{array}{l}\text { 2. UK a green arrow-shaped light which is part of a set of traffic } \\
\text { lights and which tells drivers when they can turn left or right. }\end{array}$ \\
$\begin{array}{l}\text { 3. To appear or happen gradually or to a limited degree. } \\
\text { 4. To remove solids from liquids or gases, or to remove particular } \\
\text { types of light, using special equipment. }\end{array}$
\end{tabular}

Source: Cambridge (Digital) Learner's Dictionary $3^{\text {rd }}$ Edition (2008)

For relevance and cognition (Sperber \& Wilson, 2002), the most relevant which has greater cognitive effect for innovation is "new and fresh". This because innovation posits something new which is always updated. "Double filter" mostly indicates the process of how the cigarette is created. It may be processed with the literal filtering. Other cigarettes may be filtered once, but this one is double-filtered. In Table 2, the phrase "double filters" aligns with the meaning in number 4.

At the level of relevance and comprehension (Sperber \& Wilson, 2002), "innovation double filter" explicates that a cigarette should go through a mandatory process for meeting the needs of "a healthy cigarette". This further implicates that innovation should be done to do "double filtering process". Then this finally arrives at the intended contextual implication (implication conclusion) that in order to have a cigarette which is innovative and has gone through double filter, DJARUM BLACK MILD is the right choice for smokers.

\section{Advertisement 3}

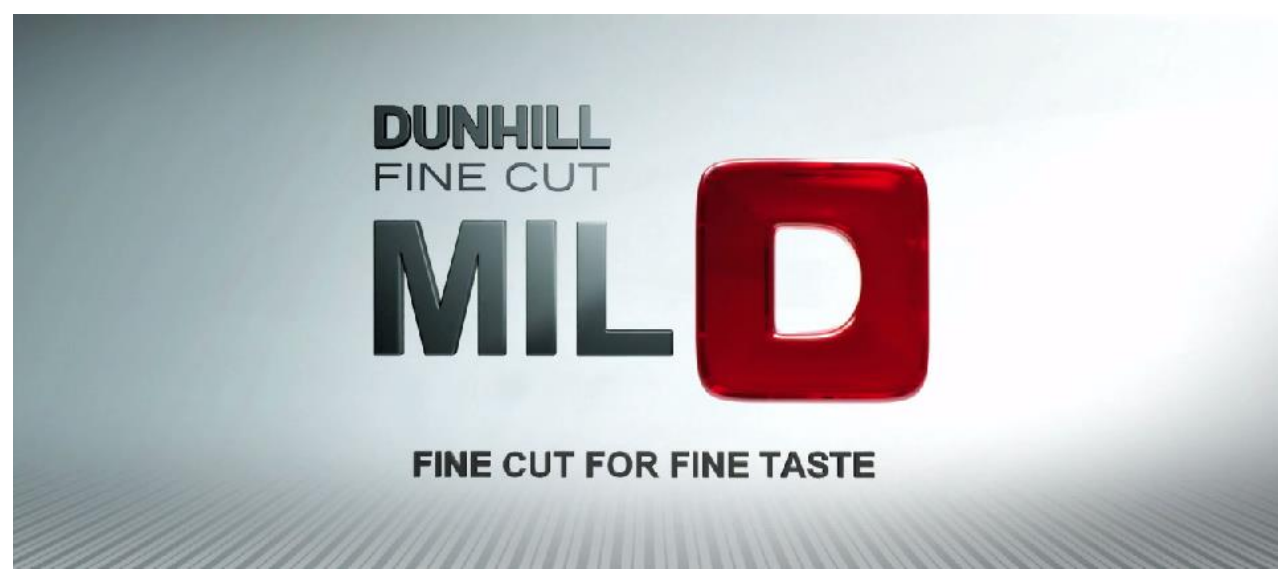

Source: "Fine Cut for Fine Taste, DUNHILL MILD” http://vimeo.com/63308242 
Table 3

Analysis of Advertisement 3

\begin{tabular}{|l|l|}
\hline Term & Possible Meaning \\
\hline Fine & $\begin{array}{l}\text { 1. Good or good enough; healthy and well (satisfactory). } \\
\text { 2. Excellent or much better than average. }\end{array}$ \\
& $\begin{array}{l}\text { 3. Very thin or in very small pieces or drops. } \\
\text { 4. Very exact and delicate, or needing to be done, treated or } \\
\text { considered very carefully. }\end{array}$ \\
\hline 5ut & $\begin{array}{l}\text { 5. Sunny and dry. } \\
\text { 7. } \text { Tax, bail, or debt. }\end{array}$ \\
& $\begin{array}{l}\text { 1. Action of cutting (with knife, scissors, etc.) to break the surface of } \\
\text { something, or to divide or make something smaller, using a sharp } \\
\text { tool, especially a knife. }\end{array}$ \\
2. To make something shorter, lower, smaller, etc. \\
3. To remove something from something else. \\
4. To not go, especially to a place where you should be - informal \\
$\quad$ American.
\end{tabular}

Source: Cambridge (Digital) Learner's Dictionary $3^{\text {rd }}$ Edition (2008)

For relevance and cognition (Sperber \& Wilson, 2002), meaning which has greater cognitive effect and greater relevance is the word "mild" is literally mild, or light, not heavy, or we can see it as the cigarette is supposed to be smoked in a relaxing condition and or a relaxing situation in a hectic workplace or a crowd, while the word "cut" means to "interrupt something or to have a rest". The word "taste" is mostly associated with "flavour". Thus for workers of any company, the cigarette product can also be used as a way out to enhance their concentration and maintain it. Without this product, they are unable to get the same amount of focus level.

Moreover, the fine cut taste explicates that a cigarette needs to have special characteristics, which is fine cut taste. Its intended contextual assumption is that fine cut taste a cigarette product is required for smokers especially in their working 
hours in order to keep focus on their works. To this end, the smokers could best smoke "DUNHILL FINE CUT MILD", the implicated conclusion of the advertisements (Sperber \& Wilson, 2002)

\section{Advertisement 4}

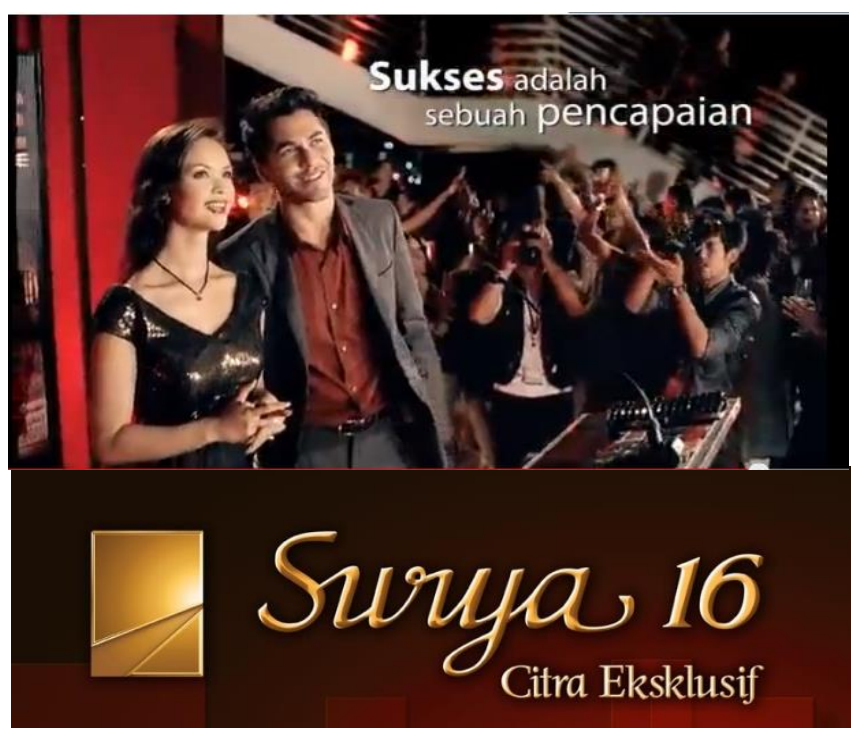

Source: "Success is an Attainment, SURYA 16, an Exclusive Image" http://www.youtube.com/watch?v=ZDKvKqHcBOE

Table 4

Analysis of Advertisement 4

\begin{tabular}{|l|l|}
\hline \multicolumn{1}{|c|}{ Term } & \multicolumn{1}{c|}{ Possible Meaning } \\
\hline Success & $\begin{array}{l}\text { 1. The achieving of the results wanted or hoped for. } \\
\text { 2. Something that achieves positive results }\end{array}$ \\
\hline Attainment & $\begin{array}{l}\text { 1. When somebody achieve something. } \\
\text { 2. The things that somebody has done and the skills they have } \\
\text { learned. }\end{array}$ \\
\hline Exclusive & $\begin{array}{l}\text { 1. Limited to only one person or group of people. } \\
\text { 2. Expensive and only for people who are rich or of a high social } \\
\text { class }\end{array}$ \\
\hline Image & $\begin{array}{l}\text { 1. A picture in mind or an idea of how someone or something is. } \\
\text { 2. The way that something or someone is thought of by other } \\
\text { people. }\end{array}$ \\
& $\begin{array}{l}\text { 3. mental picture or idea which forms in a reader's or listener's } \\
\text { mind from the words that they read or hear. }\end{array}$ \\
\hline
\end{tabular}

Source: Cambridge (Digital) Learner's Dictionary $3^{\text {rd }}$ Edition (2008)

In terms of relevance and cognition (Sperber \& Wilson, 2002), the greater effect and relevant of each word is in the following: the term "exclusive" means 
"limited people", while "image" means a "picture of the mind". Therefore, the image built by this advertisement is whether the person can feel the exclusiveness inside his own self-image to build self-confidence, aligning with exclusiveness of the cigarette. "Exclusive" has a close relation with the feel of having a high social class, which not everyone possesses. The word "success" means "a positive result" and the word "attainment" means "the thing that somebody has done". The words "success" and "attainment" are good colocation in that success is an attainment.

Strung together, the advertiser wants the audience to think that this product can encourage someone to achieve success or an attainment, which means, it needs hard work, and needs a process. It is not something to be taken for granted. And of course SURYA 16 represents an exclusive image, directed linked to the identity of those successful person. However, this explanation refers to the cigarette itself, because in the end, this is a cigarette advertisement, where every single wording of promotion should always be related to (Tungate, 2007).

In terms of relevance and comprehension (Sperber \& Wilson, 2002), the advertisements explicates that a cigarette should capture the characteristics of being: exclusive image and attaining success. The advertisements also implicates that SURYA 16 has all the features: being exclusive and success attainment. Therefore, finally the advertisement contextually concludes that SURYA 16 is the appropriate choice for smokers to show an exclusive image and for people who have attained success in their career.

\section{Conclusions}

The cigarette company represented by the advertisement team uses abstract languages to convince the smokers. These languages and expressions work well in our subconscious mind. The theme upheld in the advertisements is closely related to the expressions of limit, filter, fine taste and success, with the meaning contextualisation that has been explained earlier.

In persuading smokers, the cigarette companies go through several processes: choosing inputs which have greater relevance and greater cognitive effects; then explicating the contents (messages); implicating assumptions; and finally contextually concluding the messages as discussed by Sperber and Wilson (2002). Furthermore, the advertisers also have a strong intention to make the audiences find their identities in the advertisements. Word choices (e.g., in Advertisements 2 and 3 ) have a strong emotive power to influence the people to believe or in other words, at least reflect or connect themselves to the wordings and the language used in the advertisements (Kemp, Kennet-Hensel, \& Kees, 2013). When the advertisers can successfully obtain this part as a central attention of the people, the next stage will be on how the audiences accept and appreciate the existence of that certain advertisements on television, until it stays memorable in their mind (Cappo, 2003).

There is also similarity between the messages in the language of cigarette Advertisements 1 (GG Mild break the limit) and 4 (Success is an attainment SURYA 16 Exclusive Image). These products envisage that by consuming these products, the smokers will feel as if they can break the limit and can achieve a great success 
(success is an attainment). However, in Advertisements 2 (Innovative double filter Djarum Black nild) and 3 (Dunhill fine cut mild, fine for fine taste) are in the same domain - the good cigarette making process (double filter) and the taste (fine taste). We can say that they are in the same domain because the products can be processed or filtered more than once to create a good taste.

In the final stage, the audience will most likely assume that the product advertised is in line with their identities, which therefore prompts them to buy the product aligning with their own personalities and characters (Sperber \& Wilson, 1996). This might be the reasons why advertisers project particular identities on their product so that the people or the majority of the society would choose them. However, we believe that the patterns or the generalisations of the explanations and evidences above can still be drawn out and all the interpretations given here remain subjective.

\section{References}

Abe, H. (2010). Queer Japanese: Gender and sexual identities through linguistic practices. New York: Palgrave Macmillan.

Belch, G. E., \& Belch, M. E. (2003). Advertising and promotion: An integrated marketing communications perspective ( $6^{\text {th }}$ ed.). New York: McGraw-Hill.

Berger, A. A. (2011). Ads, fads, and consumer culture: Advertising's impact on American character and society. Plymouth: Rowman \& Littlefield Publishers, Inc.

Brierley, S. (1995). The advertising handbook. London and New York: Routledge.

Bruthiaux, P. (2000). In a nutshell: Persuasion in the spatially constrained language of advertising. Language and Communication, 20, 297-310.

Cambridge (Digital) Learner's Dictionary $3^{\text {rd }}$ Edition (2008). Cambridge: Cambridge University Press.

Cappo, J. (2003). The future of advertisement. New York: The McGraw-Hill Companies, Inc.

Chang, C. (2013). Imagery fluency and narrative advertising effects, Journal of Advertising, 42(1), 54-68.

Conrad, S. (2002). Corpus linguistic approaches for discourse analysis, Annual Review of Applied Linguistics, 22, 75-95.

Cook, G. (1992). The discourse of advertising. London and New York: Routledge.

Crichton, J. (2010). The discourse of commercialization: A multi-perspectives analysis. New York: Palgrave Macmillan.

Crook, J. (2003). On covert communication in advertising. Journal of Advertising, 36, 715-738.

Devra, D. (2008). The safer cigarette. The Ecologist, 38, 2, 44.

DiRocco, D. N., \& Shadell, W. G. (2007) Gender differences in adolescents' responses to themes of relaxation in cigarette advertising: Relationship to intentions to smoke. Addictive Behaviors, 32, 205-213

Dyer, G. (1982). Advertising as communication. London and New York: Routledge.

Freeman, D., Brucks, M., Wallendorf, M., \& Boland, W. (2009). Youths understanding of cigarette advertisements. Addictive Behaviors, 34, 36-42. 
Forceville, C. (1996). Pictorial metaphor in advertising. London and New York: Routledge.

Gardner, R., \& Luchtenberg, S., (1999). Reference, image, text in German and Australian advertising posters. Journal of Pragmatics, 32, 1807-1821.

Grice, P. 1975. Logic and conversation. Accessed February 25, 2014, from http://www.ucl.ac.uk/ls/studypacks/Grice-Logic.pdf

Goddard, A. (1998). The Language of advertising. London and New York: Routledge.

Indonesian Republic Government Rule (2003). Peraturan Pemerintah Nomor 19.

Indonesian Republic Government Rule (2012). Peraturan Pemerintah Pasal 17 Nomor 109.

Kemp, E., Kennet-Hensel, P. A., \& Kees, J. (2013). Pulling on the heartstring: Examining the effects of emotions and gender in persuasive appeals. Journal of Advertising, 42:1, 69-79.

Kostova, D. and Blecher, E. (2013). Does advertising matter?: Estimating the impact of cigarette advertising on smoking among youth in developing countries. Contemporary Economic Policy, 31, 3, 537-548.

Litosseliti, L. (Ed.) (2010). Research methods in Linguistics. London: Continuum

MaCrury, L. (2009). Advertising. London and New York: Routledge.

Martinez-Camino, G., \& Perez-Saiz, M., (2011). A Pragmatics theory on television advertising. Journal of Pragmatics, 44, 453-473.

Miles, M. B., \& Huberman, M. A. (1994). Qualitative data analysis ( $2^{\text {nd }}$ ed.). London: SAGE Publications.

McFall, L. (2004). Advertising: A cultural economy. London: SAGE Publications.

Paek, H., Reid, Leonard N. R., Jeong, H. J., Choi, H. \& Krugman, D. (2012). Five decades of promotion techniques in cigarette advertising: A longitudinal content analysis. Health Marketing Quarterly, 29, 1-17.

Rodgers, S., \& Thorson, E. (2012). Advertising theory. London/New York: Routledge.

Silverman, D. (1994). Qualitative research: Theory, method and practice ( $2^{\text {nd }}$ ed.). London: SAGE Publications.

Sperber, D., \& Wilson, D. (1996). Relevance: Communication and cognition ( $2^{\text {nd }}$ ed.). Cambridge: Blackwell.

Sperber, D., \& Wilson, D. (2002). Relevance theory. Accessed February 20, 2014, from

http://www.phon.ucl.ac.uk/publications/WPL/02papers/wilson_sperber.pdf

Tanaka, K. (1994). Advertising language: A pragmatic approach to advertisements in Britain and Japan. London and New York: Routledge.

Tungate, M. (2007). Adland: A global history of advertising. London and Philadelphia: Kogan Page.

Velasco-Sacristan, M., \& Fuertes-Olivera, A. (2006). Towards a critical cognitivepragmatic approach to gender metaphors in advertising English. Journal of Pragmatics, 38, 11, 1982-2002.

Vizcaino, M. J. G. (2011). Code-breaking/code-making: A new language approach in advertising. Journal of Pragmatics, 43(8), 2095-2109. 